Çukurova Üniversitesi Mühendislik Mimarlık Fakültesi Dergisi, 33(4), ss. 267-274, Aralık 2018

Çukurova University Journal of the Faculty of Engineering and Architecture, 33(4), pp. 267-274, December 2018

\title{
Koku Emisyonlarının Karakterizasyonu ve Ozon Kullanımı ile Gideriminin İncelenmesi
}

\author{
Melik KARA $^{* 1}$, Fulya OKAN ${ }^{1}$, Yetkin DUMANOĞLU ${ }^{1}$, Hasan ALTIOK ${ }^{1}$, \\ Abdurrahman BAYRAM ${ }^{1}$, Mustafa ODABAŞI ${ }^{1}$
}

${ }^{1}$ Dokuz Eylül Üniversitesi, Mühendislik Fakültesi, Çevre Mühendisliği Bölümü, İzmir

$\ddot{\mathbf{O} z}$

Geliş tarihi: 16.02.2018 Kabul tarihi: 25.12.2018

Bu çalışma kapsamında, kokulu gazların bileşiminde bulunan uçucu organik bileşiklerin (UOB) ve koku emisyonlarının ozonlama ile giderimi incelenmiştir. Koku kaynağı olarak aktif kümes altlı̆̆ ve arıtma çamuru kullanılmıştır. Uçucu organik bileşiklerin (UOB) kompozisyonunu gaz kromatografisikütle spektrometresi (GC-MS) cihazı, koku konsantrasyonları ise olfaktometre cihazı ile belirlenmiştir. GC-MS analizleri sonucunda 122 adet UOB, hidrokarbonlar (HC-UOB), halojenli bileşikler (Cl-UOB), azotlu bileşikler (N-UOB), oksijenli bileşikler (O-UOB) ve kükürtlü bileşikler (S-UOB) olarak gruplandırılmıştır. Aktif kümes altlığı örneklerinde baskın olarak HC'lar, O ve S içeren UOB'ler (alphapinene, methyl ethyl ketone, sec-butyl alcohol, 3-hydroxy-2-butanone, dimethyl disulfide) bulunmuştur. Balık yemi örneklerinde HC'lar ve O içeren UOB'lere rastlanmıştır (propionic acid, butanoic acid, acetic acid, hexane, methyl-cyclopentane). Arıtma çamurunda ölçülen bileşik grupları ise HC'lar, O ve S içeren UOB'lerdir (1,2,3-trimethyl-benzene, 1-ethyl-2-methylbenzene, o-propyltoluene, acetophenone, dimethyl sulfide). Uçucu organik bileşiklerin ozonlama ile giderim verimi 3 bileşik için \%100, 25 bileşik için \%98 ile $\% 80$ arasında, 42 bileşik için ise \%79 ile \%18 olarak bulunmuştur. Diğer taraftan 52 bileşiğin konsatrasyonu artmıştır. Aktif kümes altlığ 1 , balık yemi ve arıtma çamuru için koku giderim verimleri \%96,4 ile \%97,4 arasında değişmiştir. Çalışmanın sonuçları, incelenen üç farklı kaynaktaki koku seviyelerinin ozonlama ile etkin bir şekilde azaltılabileceğini ancak oluşan yeni bileşiklerin de göz önüne alınması gerektiğini göstermektedir.

Anahtar Kelimeler: Koku giderimi, Ozonlama, Uçucu organik bileşikler, Olfaktometri

\section{Characterization of Odorant Gases and Investigation of Odor Removal by Ozonation}

\begin{abstract}
In this study, the removal of volatile organic compounds (VOC) and odor emissions in odorant gasses by ozonation were investigated. Poultry litter, fish feed and sewage sludge were used as odor sources. Volatile organic compounds (VOCs) were measured by gas chromatography-mass spectrometry (GC-MS) and odor concentrations were determined by an olfactometer. As a result of GC-MS analysis, 122 VOCs were grouped as hydrocarbons (HC-VOC), halogenated compounds (Cl-VOC), nitrogen containing compounds (N-VOC), oxygenated compounds (O-VOC) and sulfur containing compounds (S-VOC). In poultry litter samples, predominantly HCs, O and S-containing VOCs (alpha-pinene, methyl
\end{abstract}

*Sorumlu yazar (Corresponding author): Melik KARA, melik.kara@deu.edu.tr 
ethyl ketone, sec-butyl alcohol, 3-hydroxy-2-butanone, dimethyl disulfide) were determined. HCs and $\mathrm{O}$-VOCs dominated the fish feed samples (propionic acid, butanoic acid, acetic acid, hexane, methylcyclopentane). Compound groups measured in treatment sludge were HCs, O-VOCs and S-VOCs (1,2,3-trimethylbenzene, 1-ethyl-2-methylbenzene, o-propyltoluene, acetophenone, dimethyl sulfide). The removal efficiencies of volatile organic compounds were $100 \%$ for 3 compounds, $98 \%$ to $80 \%$ for 25 compounds, and $79 \%$ to $18 \%$ for 42 compounds. On the other hand, the concentration of 52 compounds increased. Odor removal efficiencies for poultry litter, fish feed and sewage sludge ranged from $96.4 \%$ to $97.4 \%$. The results of the study showed that odor levels for three different sources can be effectively reduced by ozonation, however newly formed compounds should be taken into consideration.

Keywords: Odour removal, Ozonation, Volatile organic compound, Olfactometry

\section{GİRIŞ}

Koku, insanda koku alma duyusunu harekete geçiren ve kokunun algılanmasına neden olan uçucu maddelerin yarattığı etki olarak tanımlanmaktadır [1]. Koku, günümüzde önemli bir kirlilik parametresi olarak ön plana çıkmaktadır ve kokuya sebep olan uçucu organik bileşiklerin meydana getirdiği problemlerin asgari seviyelere indirilmesi gerekmektedir. Özellikle endüstriyel faaliyetler sonucu proseslerde oluşan kokulu atık gazlar atmosfere kontrolsüz olarak verilmekte ve tesislerin bulundukları bölgelerde koku emisyonu kaynaklı problemler ortaya çıkarmaktadır [2]. Oluşan kokuların rahatsız edici boyutlarda olması ve şikayetlerin artması sonucu Koku Oluşturan Emisyonların Kontrolü Hakkında Yönetmelik [1] yürürlüğe girmiş ve kokulu gazlar için sinır değerler belirlenmiştir. Bazı faaliyetlerden yayınlanan gazların sınır değerleri aşması, oluşan kokunun çeşitli teknikler kullanılarak giderilmesini gerektirmektedir.

Endüstriyel kaynaklardan yayılan kokulu maddeler hem inorganik hem de organik gazlardan (uçucu organik bileşikler, amonyak, sülfür bileşikleri, organik asitler, merkaptanlar, aldehitler ve çeşitli hidrokarbonlar) oluşmaktadır [3, 4]. Üretim faaliyetleri yanında biyolojik faaliyetler (anaerobik bozunma, kanalizasyon) sonucunda da kokulu gazlar açığa çıkmaktadır. Organik maddelerin anaerobik bozunmasından türetilen kokulu maddelerin birçoğu kükürt ve azot içermektedirler. Kokulu maddelerin birçoğu normal atmosfer koşulları altında gaz halindedirler veya en azından önemli bir uçuculuğa sahiptirler [5]. Koku sorununu yaratan faaliyetlerin başında bitkisel yağ üretimi, deri, petrokimya, şarap ve bira endüstrisi, maya üretimi, balık yemi üretimi (ekstruder sistemleri), kümes hayvanları yetiştiriciliği, tekstil sanayi, atıksu arıtma tesisleri ve rendering tesisleri gelmektedir [6]. Bu tesislerden oluşan kokuların giderimi için farklı teknikler kullanılmaktadır. Koku giderimi için kimyasal maddeler içeren çözeltiler ile yıkama, adsorpsiyon, biofiltrasyon, yakma ve ozonlama gibi yöntemler yaygın olarak kullanılmaktadır [6].

Ozon kuvvetli bir oksitleyici olmasından dolayı uzun yıllardır atıksu arıtımı ve dezenfeksiyon için kullanılmıştır. Son yillarda da güçlü oksitleyici özelliği nedeniyle koku giderici olarak ta kullanılmaktadır. Koku giderimi için kullanılan diğer kimyasalların aksine ozon, depolanamaz, üretildiği yerde hemen kullanılması gereklidir. Bu nedenle ilave depolama alanı ve tehlikeli kimyasalların yönetimine ihtiyaç duyulmaz [7]. Doğrudan atık gaz içerisine verilebileceği gibi gazın içerisinden geçtiği sıvıya verilerek de kullanılabilir [8]. Ozon sistemlerinin tasarımında dikkat edilmesi gereken başlıca husus, korozyon potansiyeli nedeniyle malzeme seçiminin ozona dayanıklılık özelliği göz önüne bulundurarak yapılmasıdır. Ozon ile koku giderimi birçok sektörde başarılı bir şekilde uygulanmaktadır. Atıksu artıma tesislerinde ozon kullanılarak koku giderimi verimi \%99'a ulaşırken, bu oran rendering tesislerinde $\% 40-100$ aralığında gerçekleşmektedir [9, 10].

$\mathrm{Bu}$ çalışma kapsamında, kokulu gazların bileşiminde bulunan uçucu organik bileşiklerin 
ozonlama ile giderimi deneysel olarak incelenmiştir. İncelenmek üzere belirlenen üç adet koku kaynağından (aktif kümes altlığı, balık yemi ve yoğunlaştırıcı çıkışı arıtma çamuru) oluşan kokulu gazlar, oluşturulan pilot ölçekli bir ozonlama kolonundan geçirilerek koku giderim verimleri ve oluşan gazların uçucu organik bileşik (UOB) kompozisyonları belirlenmiştir. Kokulu gazlar, uçucu organik bileşiklerin kompozisyonunu belirlemek amacı ile gaz kromatografisi-kütle spektrometresi (GC-MS) cihazı kullanılarak analizlenirken koku konsantrasyonlarını belirlenmek amacı ile olfaktometre cihazı kullanılmıştır.

\section{MATERYAL VE METOD}

\subsection{Koku Kaynakları}

Çalışmada koku giderim verimlerinin incelenmesi amacıyla üç adet farklı koku oluşturan kaynak seçilmiştir. Bunlar, kümes hayvanları yetiştiriciliğini temsilen aktif kümes altlığ1, ekstruder sistemini ve hayvan yemi üretimini temsilen balık yemi ve artıma tesislerini temsilen yoğunlaştırıcı çıkışı arıtma çamurudur.

Aktif kümes altlı̆̆ çiftliğinden sağlanmıştır. Bu tür kanatlı hayvan yetiştirme kümeslerinde altlık materyali olarak kaba odun talaşı, saman, hızar talaşı, kâğıt kırpıntıları, ayçiçeği kabuğu, çeltik kavuzu, taze findık cürufu, mısır silajı, kum, kompostlanmış altlık, çam kabuğu, parçalanmış mısır koçanı, diatomit ve ponza kullanılabilmektedir. Kümes altlığının yapısı birçok faktöre bağlı olarak değişmekle birlikte dışkı (\%62), altlık materyali $(\% 31)$, döküntü yem (\%3), tüy $(\% 2)$ ve diğer atıklardan (\%2) oluşmaktadır. Benzer şekilde kullanılan altlığın türü ve kullanım sıklığına bağlı olarak değişen düzeylerde (E. coli, Staphylococcusspp., Clostridiumperfringens, Campylobacterspp ve Salmonella spp. gibi) patojenleri içerebilmektedir [11]. Aktif kümes altlığında kokuya neden olan bileşikler; karboksilik asitler, hidrokarbonlar, alkoller, aldehitler, aminler, aromatikler, fenoller, uçucu yağ asitleri, $\mathrm{S}$ içeren bileşikler, $\mathrm{N}$ içeren bileşikler, ketonlar ve indoller olarak siralanabilir [12]. Balık yemi örnekleri bölgede faaliyet gösteren ekstruder sistemi ile balık yemi üreten bir tesisten sağlanmıştır. Balık yemi bileşiminde balık unu, balık yağı, çeşitli bitki tohumları unu (buğday, mısır), soya küspesi, pamuk tohumu küspesi ayçiçeği tohumu küspesi ve mısır glüteni bulunmaktadır. Ekstruder sistemi ise balık yeminin belirli bir oranda buhar ve suyla pişirilerek bazı hammaddelerden gelen ve hastalığa neden olan zararlı maddelerin yok edilmesi ve besinlerden maksimum yararın sağlanması için geliştirilmiş bir üretim sistemidir. Son kaynak olarak seçilen artıma çamuru örnekleri ise, deri yoğunluklu karma bir organize sanayi bölgesi atıksu arıtma tesisinin çamur susuzlaştırma ünitesi çıkışından alınmıştır. Burada çamurun susuzlaştırılması için dekantör kullanılmakta ve katı madde içeriği \%3540'lara ulaşmaktadır. Arıtma tesislerinden ağırlıklı olarak monoaromatikler (örneğin benzen, toluen), halojenli bileşikler (klorobenzen), aldehitler (hekzanal, proponal), ketonlar (örn. Aseton), esterler, terpenler, merkaptanlar, indirgenmiş sülfür bileşikleri (yani hidrojen sülfür, dietil sülfür), uçucu yağ asitleri ve çeşitli UOB'ler atmosfere koku oluşturan bileşikler olarak salınmaktadır [13, 14].

\subsection{Deneysel Çalışmalar ve Örnekleme}

Çalışmanın deneysel bölümünde kokulu gazlar ile ozon pilot ölçekli bir kolon reaktörden geçirilerek ozonun koku giderim verimi belirlenmiştir.

Çalışma süresince koku kaynağının ve hava akışının sürekli olması için alınan kokulu madde örnekleri 30-40 ${ }^{\circ} \mathrm{C}^{\prime}$ ye kadar 1sitılan bir kap içerisine konularak, aktif karbon kolonundan geçirilip safsızlaştırılan ortam havası ile sürekli beslenmiştir. Bunun sonucunda sürekli bir kokulu gaz akışı sağlanmıştır. Elde edilen kokulu gaz 900$1000 \mathrm{~L} /$ saat akış debisi ile kolona gönderilmiştir. Diğer taraftan ozon jeneratöründe üretilen 0,25 g/saat ozon, 0,3 L/dk akış debisi ile kolona gönderilmiştir. Kolon içerisinde kokulu gaz ile ozonun reaksiyona girmesi sağlanarak giderim gerçekleştirilmiştir. Çalışmada $3 \mathrm{~m}$ boyunda $6 \mathrm{~cm}$ çapında, reaksiyon için gerekli temasın ve alıkonma süresinin sağlanması amacıyla tasarlanmış perde yapısı bulunan kolon reaktör 
kullanılmıştır. Her bir perde $4 \mathrm{~cm}$ aralık ve $45^{\circ}$ yatay açı ile yerleştirilmiştir (Şekil 1).
Şekil 2'de deney düzeneği ve örnekleme noktaları gösterilmektedir.

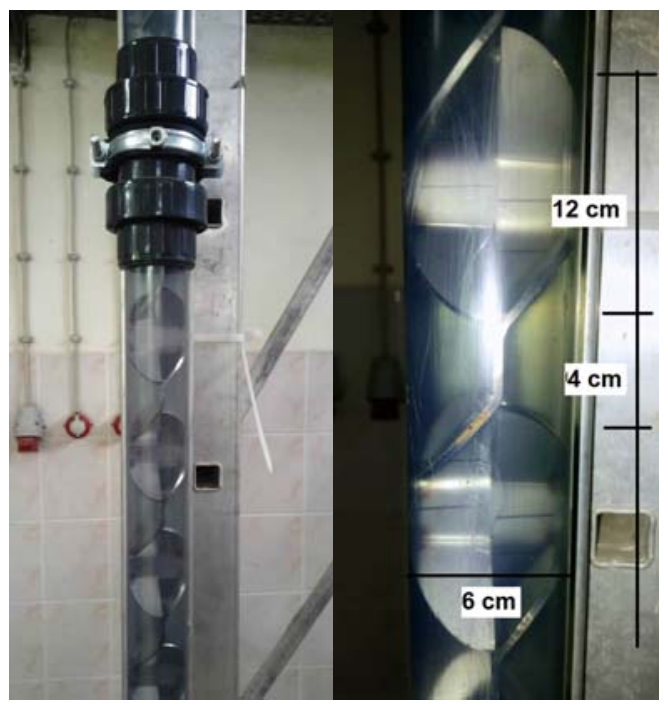

Şekil 1. Çalışmada kullanılan reaktör tasarımı

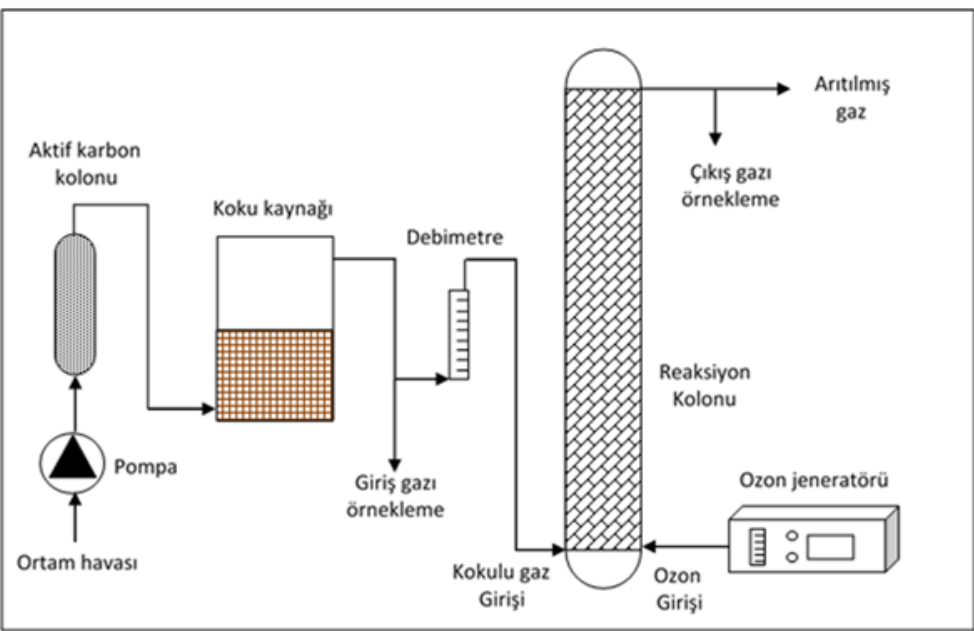

Şekil 2. Ozonlamada kullanılan deney düzeneğinin akım şeması

Koku örnekleri, girișten ve çıkıș noktalarından her bir koku kaynağı için 2 tekrarlı olmak üzere Nalophan torbalar içerisine alınmıştır. Örneklerin birisi koku birimi cinsinden konsantrasyonunun belirlenmesi için olfaktometrik yöntem koku ölçümü için kullanılmıştır. Diğeri ise $0,5 \mathrm{~L} / \mathrm{dk}$ debi ve $10 \mathrm{dk}$ süreyle adsorban tüplere (Tenax) örneklenerek GS-MS (Gaz Kromatografisi-Kütle Spektrometresi) cihazında analizlenmiştir.

\subsection{Koku Ölçümü ve Uçucu Organik Bileşiklerin Analizi}

Toplanan kokulu gaz örneklerinin koku konsantrasyonlarının belirlenmesi amaciyla ECOMA T07 Model Olfaktometre sistemi kullanılmıştır. Örnek torbası olfaktometreye bağlandıktan sonra nötr hava ile seyreltilerek daha önceden belirlenen panelistler tarafindan 
koklanarak gerçekleștirilmiștir. Tüm panelistler verilen kokuyu hissedinceye kadar seyreltme oranları azaltılmış ve tüm panelistlerin kokuyu hissettiği anda ölçüm sonlandırılarak koku konsantrasyonları Koku birimi $(\mathrm{KB}) / \mathrm{m}^{3}$ olarak belirlenmiştir [15]. Koku ölçümleri 4 panelist ve 1 panel liderinden oluşan grup tarafından gerçekleştirilmiştir. Ölçülen koku konsantrasyonları, alınan 2 tekrarlı 3 farklı örneğin $3 \mathrm{kez}$ tekrarlanmasiyla elde edilen 18 sonucun geometrik ortalaması hesaplanarak belirlenmiştir.

GS-MS cihazında, uçucu organik bileşikler (UOB) kompozisyonu belirlemek amaciyla Tenax tüplere alınan koku örnekleri, helyum akımı kullanılarak desorblanmıştır. Kromatografik kolon olarak HP5MS (30 m, 0,25 mm, 0,25 $\mu \mathrm{m})$, taşıyıcı gaz olarak ise helyum kullanılmıştır. Termal desorber sistemini kalibre etmek için analizlenen bileşiklerin bir bölümünü içeren bir standart karışımından metanol ile seyreltilerek kalibrasyon standartları hazırlanmıştır. Analizlenmesi hedeflenen bileşiklerin büyük bir çoğunluğu için analitik standart maddeler mevcut olmadığı için bu bileşikler, kendilerine benzer bileşiklerin (fizikokimyasal özellikleri ve kütle spektrometresindeki iyonizasyon paternleri çok benzer olan ve aynı grup içerisinde bulunan bileşikler) standartları kullanılarak yarı kantitatif olarak analizlenmiștir. Analizler sonucunda, spektral kütüphane taramaları kullanılarak 122 adet UOB belirlenmiştir.

\section{SONUÇLAR}

\subsection{Olfaktometrik Yöntem ile Ölçülen Koku Konsantrasyonları}

Çalışmada, Olfaktometrik yöntem ile 3 koku kaynağ1 (aktif kümes altlığı, balık yemi ve yoğunlaştırıcı çıkışı arıtma çamuru) için koku konsantrasyonları ve ozonlama ile arıtım sonucunda oluşan koku konsatrasyonları ölçülmüştür. Olfaktometrik koku ölçümleri sonucunda reaktör giriş ve çıkışında ölçülen koku konsantrasyonları Çizelge 1'de verilmektedir. En yüksek değer aktif kümes altlığ1 için ölçülürken, yoğunlaştırıcı çıkışı arıtma çamuru ve balık yemi üretimi onu izlemiştir. Ozonlama ile koku giderimi çalışması sonucunda giriş ve çıkıs koku konsantrasyonları karşılaştırıldığında, koku giderim veriminin aktif kümes altlığı için \%97,4; balık yemi için \%96,4 ve arıtma çamuru için \%97,2 oranında olduğu belirlenmiştir.

Çizelge 1. Olfaktometrik yöntem ile belirlenen giriş ve çıkış konsantrasyonları $\left(\mathrm{KB} / \mathrm{m}^{3}\right)$

\begin{tabular}{|l|c|c|c|}
\hline \multirow{2}{*}{$\begin{array}{l}\text { Örnekleme } \\
\text { Noktası }\end{array}$} & \multicolumn{3}{|c|}{ Koku Kaynağ } \\
\cline { 2 - 4 } & $\begin{array}{c}\text { Kümes } \\
\text { Altlı̆̆ } 1\end{array}$ & $\begin{array}{c}\text { Balık } \\
\text { Yemi }\end{array}$ & $\begin{array}{c}\text { Arıtma } \\
\text { Çamuru }\end{array}$ \\
\hline Reaktör Girişi & 11000 & 5300 & 7100 \\
\hline Reaktör Çıkış1 & 290 & 190 & 200 \\
\hline
\end{tabular}

Şahin [6] tarafından yapılan çalışmada atıksu arıtma ve çamur uzaklaştırma tesislerinde ölçülen ham koku konsantrasyonlarının, bu çalışmada ölçülen değerlere benzer olarak 2754-13325 KB/m³ $(n=12)$ aralığında değiştiği rapor edilmiştir. Diğer taraftan Dokuz Eylül Üniversitesi Hava Kirliliği laboratuvarı tarafından gerçekleştirilen Balık yemi üretimine ait koku ölçümlerinde ham koku değerlerinin 6846-14930 KB/m $\mathrm{m}^{3} \quad(\mathrm{n}=6)$ aralığında değiştiği rapor edilmiştir [16].

\subsection{Kokulu Gazların Bileșiminde Bulunan Uçucu Organik Bileşikler ve Konsantrasyonları}

Kokulu gazların bileşiminde bulunan uçucu organik bileşiklerin karakterize edilmesi amaciyla alınan örneklerde, GC-MS analizleri sonucunda, spektral kütüphane taramaları kullanılarak 122 adet UOB belirlenmiștir. $\mathrm{Bu}$ bileșikler, hidrokarbonlar (HC-UOB), halojenli bileşikler (Cl-UOB), azotlu bileşikler (N-UOB), oksijenli bileşikler (O-UOB) ve kükürtlü bileşikler (S-UOB) gruplarına ait bileşiklerdir. Çalışma sonucunda, toplam uçucu organik bileşik konsantrasyonları sırasıyla reaktör giriş ve çıkışında aktif kümes altlığ 1 için 4026 ve $5351 \mu \mathrm{g} / \mathrm{m}^{3}$; balık yemi için 1813 ve $3225 \mu \mathrm{g} / \mathrm{m}^{3}$; arıtma çamuru için 914 ve $2068 \mu \mathrm{g} / \mathrm{m}^{3}$ olarak ölçülmüştür. Buna göre tüm koku kaynaklarında toplam organik bileşik konsantrasyonunun ozonla reaksiyon sonucunda arttığı görülmüştür. Aktif kümes altlığı için reaktör çıkışı örneklerinde $\mathrm{N}$ ve O'li bileşikler oluşmuştur. Konsantrasyonları artan bileşikler 
N,N-dimethylformamide, cyclohexanone ve acetone'dur. Balık yemi için konsantrasyonu artan bileşikler alpha-chloroacetophenone (Cl-UOB), phenylethyne

(HC-UOB), N,N-dimethylformamide (N-UOB), benzonitrile (N-UOB), formic acid (O-UOB) ve 2-hydroxy-1-phenyl-ethanone (O-UOB)'dir. Arıtma çamuru örneklerinde ise ozonlama sonucunda konsantrasyonu artan bileşikler N,N-dimethylformamide (N-UOB), benzonitrile (N-UOB), acetone (O-UOB), acetic acid (O-UOB), cyclohexanone (O-UOB), benzaldehyde (O-UOB) ve acetophenone (O-UOB)'dur.

Aktif kümes altlığından alınan örneklerde baskın olarak HC'lar, $\mathrm{O}$ ve $\mathrm{S}$ içeren UOB'ler bulunmuştur. En yüksek konsantrasyona sahip bileşikler sirasıyla methyl ethyl ketone (1375 $\left.\mu \mathrm{g} / \mathrm{m}^{3}\right)$, sec-butyl alcohol $\left(685 \mu \mathrm{g} / \mathrm{m}^{3}\right)$, dimethyl disulfide $\left(385 \mu \mathrm{g} / \mathrm{m}^{3}\right)$, alpha-pinene'dir $\left(232 \mu \mathrm{g} / \mathrm{m}^{3}\right)$. Balık yemi örneklerinde çoğunlukla HC'lar ve O içeren UOB'lere rastlanmıştır. En yüksek konsantrasyona sahip bileşikler acetic acid $\left(445 \mu \mathrm{g} / \mathrm{m}^{3}\right)$, propionic acid $\left(233 \mu \mathrm{g} / \mathrm{m}^{3}\right)$, butanoic acid $\left(180 \mu \mathrm{g} / \mathrm{m}^{3}\right)$, hexanal $\left(153 \mu \mathrm{g} / \mathrm{m}^{3}\right)$ ve hexane'dır $\left(103 \mu \mathrm{g} / \mathrm{m}^{3}\right)$. Arıtma çamurunda gözlenen başlıca bileşik grupları ise $\mathrm{HC}^{\prime}$ lardır. $\mathrm{Bu}$ bileşikler 1,2,3-trimethyl-benzene (114 $\left.\mu \mathrm{g} / \mathrm{m}^{3}\right)$, 1-ethyl-2-methyl-benzene $\quad\left(76 \mu \mathrm{g} / \mathrm{m}^{3}\right)$, o-propyltoluene $\left(55 \mu \mathrm{g} / \mathrm{m}^{3}\right)$ ve hexane'dir $\left(52,1 \mu \mathrm{g} / \mathrm{m}^{3}\right)$.

Şekil 3'te reaktör giriş ve çıkışında alınan numunelerde ölçülen toplam $\mathrm{Cl}, \mathrm{HC}, \mathrm{N}, \mathrm{O}$ ve S-UOB konsantrasyonları verilmiştir. Aktif kümes altlı̆g1 örneklerinde O' li bileşikler girişte $3257 \mu \mathrm{g} / \mathrm{m}^{3}$, çıkışta ise $1395 \mu \mathrm{g} / \mathrm{m}^{3}$ olarak tespit edilmiştir. Kükürtlü uçucu organik bileşiklerin giriş konsantrasyonu 442,1 $\mu \mathrm{g} / \mathrm{m}^{3} \quad$ çıkış konsantrasyonu $57,9 \mu \mathrm{g} / \mathrm{m}^{3}$ olarak ölçülmüştür. $\mathrm{N}$ 'lu uçucu organik bileşiklerin giriş konsantrasyonu $34,3 \mu \mathrm{g} / \mathrm{m}^{3}$ olarak görülürken çıkıştaki konsantrasyon değeri $3,862 \mu \mathrm{g} / \mathrm{m}^{3}$ olarak ölçülmüştür. HC'ların giriş konsantrasyonu $292,8 \mu \mathrm{g} / \mathrm{m}^{3}$ olup çıkış konsantrasyonu ise $35,9 \mu \mathrm{g} / \mathrm{m}^{3}$, tür. $\mathrm{Cl}$ içeren uçucu organik bileşikler tespit edilememiştir. Aktif kümes altlı̆̆ örneklerinde HC'ların, O, S içeren uçucu organik bileşiklerin giriş konsantrasyonunun yüksek olduğu saptanmıştır. N-UOB bileşiklerinde ise reaktör çıkışında artış görülmüştür.

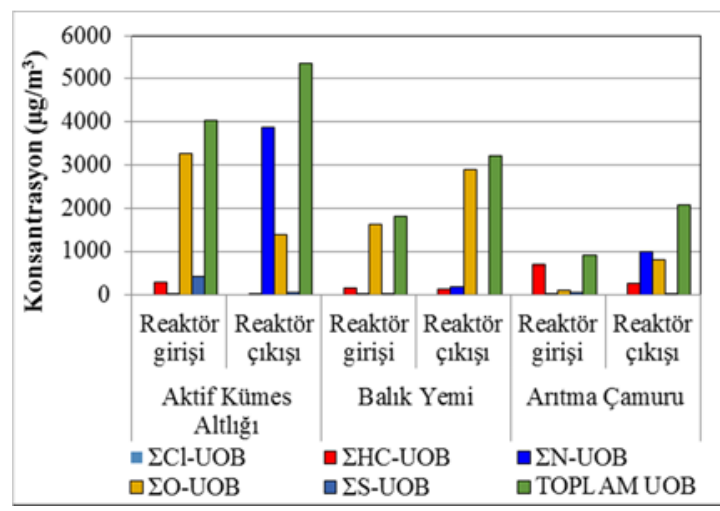

Şekil 3. Koku kaynakları için farklı UOB gruplarına göre giriş ve çıkış konsantrasyonlar1

Balık yemi örneklerinde O'li bileşikler girişte $1616 \mu \mathrm{g} / \mathrm{m}^{3}$, çıkışta ise $2890 \mu \mathrm{g} / \mathrm{m}^{3}$ olarak tespit edilmiştir. Ozonlama sonucunda O-UOB'in konsantrasyonunda artış olduğu gözlenmiştir. HC-UOB'in giriş konsantrasyonu 175,3 $\mu \mathrm{g} / \mathrm{m}^{3}$ çıkış konsantrasyonu ise $132,5 \mu \mathrm{g} / \mathrm{m}^{3}$ olarak ölçülmüştür. N'lu uçucu organik bileşiklerin giriş konsantrasyonu $17,8 \mu \mathrm{g} / \mathrm{m}^{3}$ olarak görülürken çıkıştaki konsantrasyon değeri $186,5 \mu \mathrm{g} / \mathrm{m}^{3}$ olarak ölçülmüştür. $\mathrm{Bu}$ arada $\mathrm{N}$ 'lu bileşiklerinin giderilmediği, çıkış konsantrasyonunun giriş konsatrasyonundan yaklaşık 10 kat daha yüksek olduğu saptanmıştır. S'lü bileşiklerin giriş konsantrasyonu $2,7 \quad \mu \mathrm{g} / \mathrm{m}^{3} \quad$ olup çıkış konsantrasyonu ise tespit limitinin altındadır. $\mathrm{Cl}$ içeren uçucu organik bileşikler girişte $0,63 \mu \mathrm{g} / \mathrm{m}^{3}$ çıkışta ise $16,1 \mu \mathrm{g} / \mathrm{m}^{3}$ olarak tespit edilmiştir.

Arıtma çamuru örneklerinde ise HC'lar girişte $689,8 \mu \mathrm{g} / \mathrm{m}^{3}$, çıkışta ise $263,7 \mu \mathrm{g} / \mathrm{m}^{3}$ olarak tespit edilmiştir. O'li bileşikler giriște $123 \mu \mathrm{g} / \mathrm{m}^{3}$, çıkıșta ise $802 \mu \mathrm{g} / \mathrm{m}^{3}$ olarak tespit edilmiştir ve O-UOB'ler giderilmemiştir. N-UOB'in giriş konsantrasyonu $31,9 \mu \mathrm{g} / \mathrm{m}^{3}$ çıkış konsantrasyonu ise $996,5 \mu \mathrm{g} / \mathrm{m}^{3}$ olarak ölçülmüştür. $\mathrm{O}$ ve $\mathrm{N}^{\prime} \mathrm{lu}$ uçucu organik bileşikler için çıkış konsantrasyonlarının giriş konsantrasyonlarından çok daha fazla olduğu görülmektedir. S‘lü uçucu 
organik bileşiklerin giriş konsantrasyonu 64,2 $\mu \mathrm{g} / \mathrm{m}^{3}$ olarak görülürken çıkştaki konsantrasyon değeri $3,1 \quad \mu \mathrm{g} / \mathrm{m}^{3} \quad$ olarak ölçülmüştür. $\quad \mathrm{Cl}$ 'lu bileşiklerin giriş konsantrasyonu $4,61 \quad \mu \mathrm{g} / \mathrm{m}^{3} \quad$ olup çı1ş̧ konsantrasyonu ise $2,99 \mu \mathrm{g} / \mathrm{m}^{3}$ 'tür.

Tüm koku kaynaklarında N-UOB'nin ozonlama sonrasında ozonun yüksek oksitleyici özelliği nedeniyle konsantrasyonlarında artış görülmüştür. $\mathrm{Bu}$ durumun özellikle Aktif kümes altlı̆̆ındaki yüksek $\mathrm{NH}_{3}$ (amonyak) konsantrasyonlarına bağlı olduğu düşünülmektedir. Ayrıca, arıtma çamurundaki benzer durum da bunu desteklemektedir. Sonuçlar bileşik bazında değerlendirildiğinde, ozonlama sonucunda ölçülen 122 UOB içerisinden 52 bileşiğin konsantrasyonunda artış olmuştur. Ozon ile reaksiyon sonucunda konsantrasyonunda en fazla artış olan bileşikler N-UOB grubunda $\mathrm{N}, \mathrm{N}$-dimethylformamide ve O-UOB grubunda ise methyl ethyl ketone iken, en az artış gösteren bileşikler ise O-UOB grubundan 2-acetylfuran ve methyl sec-butyl ketone'dur.

Ozonlama sonucunda en yüksek giderim oranına sahip bileşik grubu ise S-UOB'dir. Tavuk altlığında \%86 oranında, balık yeminde \%100 oranında ve arıtma çamurunda \%95 oranında giderim sağlanmıştır. Bununla birlikte, O-UOB grubundan trans-2-hexenal, N-UOB grubundan 2,5-dimethylpyrazine ve S-UOB grubundan S-methyl thiobutyrate bileşiklerinde $\% 100$ verimle giderim sağlanmıştır. $\mathrm{Bu}$ giderim yöntemi ile 69 adet Cl-UOB, HC-UOB, N-UOB, O-UOB ve S-UOB gruplarına ait bileşik giderilmiştir. Diğer taraftan, N-UOB grubundan 2-ethyl-3,6-dimethylpyrazine, O-UOB grubundan da 2-pentanol bileşiklerinin giderim verimlerinin oldukça düşük olduğu görülmüştür.

\section{SONUÇLAR}

Bu çalışmada koku kaynağı olarak etkin bir şekilde kokulu emisyonlara sebep olan proseslerdeki koku ve uçucu organik bileşik konsatrasyonları belirlenmiştir. Kokuya sebep olan bileşiklerin ve koku emisyonlarının ozonlama ile arıtımı neticesinde nasıl değiştiği arıtılmış gazın karakterizasyonu yapılarak tespit edilmiştir. Çalışma bu açıdan ülkemizde gerçekleştirilen kapsamlı çalışmalardan birisidir.

Ozonlama sonucunda kokuya neden olan uçucu organik bileşiklerin azaldığı ve böylece kokunun önemli ölçüde bertaraf edildiği tespit edilmiştir. Deneysel çalışmalarda kullanılan tüm koku kaynakları (aktif kümes altlığı, balık yemi ve yoğunlaştırıcı çıkışı arıtma çamuru) için yüksek koku giderim verimleri $(\% 96,4-97,4)$ elde edilmiştir. Bu nedenle ozonlamanın koku giderimi için etkin bir yöntem olduğu söylenebilir.

Çalışmanın diğer kısmında 3 farklı koku kaynağı için arıtılmamış ve arıtılmış kokulu gaz örneklerinin organik kirleticiler açısından karakterizasyonu yapılmıştır. Literatürde gerçekleştirilen benzer çalışmalarda, Murphy ve arkadaşları [17] 5 farklı kümesten aldığı koku örneklerinde en fazla sirasiyla dimethyl sulfide, dimethyl trisulfide, 2-3 butanedione, 3-methyl-butanal, 1-butanol, 3-methyl-1-butanol, acetoin ve 2-butanone bileşiklerini ölçerken, Huffel ve arkadaşları [18] ethanoic acid, propanoic acid, butanoic acid ve kükürtlü bileşik konsatrasyonlarının yüksek olduğunu belirlemiştir. Diğer taraftan, bu çalışmada arıtma tesisi çamurunda baskın olarak HC'lar grubundan 1,2,3-trimethyl-benzene, 1-ethyl-2-methylbenzene, o-propyltoluene ve hexane yüksek konsantrasyonlarda ölçülürken benzer olarak Kaohsiung City, Tayvan'da yapılan çalışmada [19] chloroethene, trichloroethene, toluene, tetrachloroethene, acetone, m/p-xylene, o-xylene, ethylbenzene evsel atıksu artıma tesisi kokulu gazlarında yüksek konsatrasyonlarda ölçülmüştür.

$\mathrm{Bu}$ çalışmanın önemli bir bulgusu ise uçucu organik bileşiklerin karakterize edilmesi çalışmaları sonucunda giriş örneklerindeki bazı grup ve bileşiklerin konsantrasyonlarının azalırken, bazı grup ve bileşiklerin ise ozon reaksiyonları sonucunda arttığının belirlenmesidir. $\mathrm{Bu}$ durumda ozonlama ile koku gideriminde oluşacak olan yeni bileşiklerin çevre ve insan 
sağlığı açısından oluşturabileceği etkiler göz önünde bulundurulmalıdır.

\section{KAYNAKLAR}

1. KOEKHY, 2010. Koku Oluşturan Emisyonların Kontrolü Hakkında Yönetmelik. Resmi Gazete. Say1: 28712, Ankara.

2. Güler, U., 2015. Gida Fermantasyon Prosesinden ve Organik Kimya Sektöründen Kaynaklanan Koku Emisyonlarının Karakterizasyonu, Yüksek Lisans Tezi, İstanbul Teknik Üniversitesi, Fen Bilimleri Enstitüsü.

3. Mudliar, S., Giri, B., Padoley, K., Satpute, D., Dixit, R., Bhatt, P., Pandey R, Juwarkar, A., Vaidya, A., 2010. Bioreactors for Treatment of VOCs and Odours-a Review. Journal of Environmental Management, 91, 1039-1054.

4. Barbusinski, K., Kalemba, K., Kasperczyk, D., Urbaniec, K., Kozik, V., 2017. Biological Methods for Odor Treatment-A Review. Journal of Cleaner Production, 152, 223-241.

5. Akyüz, F., 2016. Endüstriyel Kokular ve Etkileri. Turkchem Dergisi, 50, 14-18.

6. Şahin, E., 2017. Determination of Odor Sources in Different Industrial Sectors and Selection of Appropriate Control Techniques, MSc Thesis, Dokuz Eylul University, Izmir.

7. Zhang,Y., Pagilla, K., R., 2013. Gas-Phase Ozone Oxidation of Hydrogen Sulfide for Odor Treatment in Water Reclamation Plants. Ozone: Science \& Engineering: The Journal of the International Ozone Association 35, 390-398.

8. Smet, E., Lens, P., Van Langenhove, H., 2010. Treatment of Waste Gases Contaminated with Odorous Sulfur Compounds, Critical Reviews in Environmental Science and Technology, 28, 89-117.

9. Kerc, A., Olmez, S.S., 2010. Ozonation of Odorous Air in Wastewater Treatment Plants. Ozone: Science \& Engineering, 32, 199-203.

10. American Society of Agricultural and Biological Engineers, (ASABE), 2003. The Potential of Coupling Biological and Chemical/physical Systems for Air Pollution Control: A Case Study in the Rendering
Industry. https://elibrary.asabe.org/abstract.asp ?aid $=15500 \& \mathrm{t}=2 \&$ redir $=\&$ redirType $=$ ). Erişim Tarihi Ağustos 2017.

11. Şekeroğlu, A., Eleroğlu, H., Sarıca, M., Camcı, Ö., 2013. Yerde Üretimde Kullanılan Altlık Materyalleri ve Altlık Yönetimi. Tavukçuluk Araştırma Dergisi, 10, 27-28.

12. Zhang, S., Cai, L., Koziel, J.A., Hoff, S.J., Schmidt, D.R., Clanton, C.J., Jacobson, L.D., Parker, D.B., Heber, A.J., 2010. Field Air Sampling and Simultaneous Chemical and Sensory Analysis of Livestock Odorants with Sorbent Tubes and GC-MS/olfactometry. Sensors and Actuators B: Chemical, 146, 427-432.

13. Dincer, F., 2007. Characteristic and Chemistry of Odors from Selected Industrial Facilities in Izmir, Ph. D Thesis, Dokuz Eylül University, İzmir.

14. Dincer, F., Muezzinoglu, A., 2008. Odorcausing Volatile Organic Compounds in Wastewater Treatment Plant Units and Sludge Management Areas. Journal of Environmental Science and Health Part A, 43, 1569-1574.

15. European Committee for Standardization (CEN), 2003. EN 13725-Determination of Odour Concentration by Dynamic Olfactometry.

16. Dokuz Eylül Üniversitesi, 2018. Hava Kirliliği Laboratuvarı Koku Ölçüm Raporları, İzmir.

17. Murphy, K.R., Parcsi, G., Stuetz, R.M., 2014. Non-methane Volatile Organic Compounds Predict Odor Emitted from Five Tunnel Ventilated Broiler Sheds. Chemosphere, 95, 423-432.

18. Huffel, K.V., Heynderickx, P., Dewulf, J., Langenhove, H.V., 2012. Measurement of Odorants in Livestock Buildings: SIFT-MS and TD-GC-MS. Chemical Engineering Transactions, 30, 67-72.

19. Huang, C.H., Chen, K.S., Wang, H.K., 2012. Measurements and PCA/APCS Analyses of Volatile Organic Compounds in Kaohsiung Municipal Sewer Systems, Southern Taiwan. Aerosol and Air Quality Research, 12, 1315-1326. 